\title{
Contextual control over lexical and sublexical routines when reading English aloud
}

\author{
MICHAEL REYNOLDS and DEREK BESNER \\ University of Waterloo, Waterloo, Ontario, Canada
}

\begin{abstract}
Are the processes responsible for reading aloud single well-formed letter strings under contextual control? Despite the widespread contention that the answer to this question is "yes," it has been remarkably difficult to provide a compelling demonstration to that effect. In a speeded naming experiment, skilled readers read aloud exception words (such as PINT) that are atypical in terms of their spelling sound correspondences and nonwords (such as FLAD) that appeared in a predictable sequence. Subjects took longer to name both words and nonwords when the item on the preceding trial was from the other lexical category, relative to when the preceding item was from the same lexical category. This finding is consistent with the relative contributions of lexical and sublexical knowledge being controlled. We note a number of different ways that this control could arise and suggest some directions for future research.
\end{abstract}

Learning how to translate print into a phonological code is, for most children, critical for learning how to read. Many theorists think that this ability is also functionally important for skilled readers (see Frost's 1998 review). One major account of this skill is provided by the dual-route cascaded (DRC) model (Coltheart, Rastle, Perry, Langdon, \& Ziegler, 2001). The DRC model has two ways of converting print to sound without semantic involvement. One relies on sublexical spelling-sound correspondence rules (the nonlexical route), and the other relies on whole-word associations between orthography and phonology (the lexical route).

The dual-route architecture is central to the DRC model's account of reading aloud because neither route alone can lead to the correct reading aloud of all types of stimuli. The nonlexical route generates a correct pronunciation for regular words (HINT) and nonwords (FINT) on the basis of spelling-sound correspondence rules but not for items that violate these rules. Instead, it regularizes them (e.g., exception words like PINT are read so as to rhyme with regular words like MINT). The lexical route generates a correct pronunciation for regular words and exception words on the basis of orthographic and phonological whole-word representations. This route cannot name nonwords correctly, because they are not represented in the lexicons. Critically though, both routes for translating print into sound are active, irrespective of the stimulus being named.

One question that arises naturally in the context of a theory with multiple procedures for converting print into sound is whether any of these processes can be contextually or strategically controlled. There have been a num-

This research was supported by Grant A0998 from the Natural Sciences and Engineering Research Council of Canada to D.B. and a doctoral fellowship to M.R. Correspondence concerning this article should be addressed to M. Reynolds, Department of Psychology, University of Waterloo, Waterloo, ON, N2L 3G1 Canada (e-mail: mg2reynolds@ uwaterloo. ca). ber of attempts to demonstrate such control when single words and nonwords are read aloud under blocked and mixed conditions (e.g., Baluch \& Besner, 1991; Rastle \& Coltheart, 1999; Tabossi \& Laghi, 1992; Zevin \& Balota, 2000). All of these authors reported reaction time (RT) data consistent with the interpretation that control can be exerted over whether the lexical or nonlexical routine will dominate performance. However, the same data have also been argued to be consistent with subjects changing their time criterion for responding. Indeed, this time criterion account, which does not appeal to a shift in the relative dominance of one processing routine over the other, may provide a better explanation of these RT data ${ }^{1}$ (Chateau \& Lupker, 2003; Kinoshita \& Lupker, 2002, 2003; Lupker, Brown, \& Colombo, 1997; Taylor \& Lupker, 2001; see also Raman, Baluch, \& Besner, 2004). The present work therefore adopts a different approach in an effort to demonstrate contextual control over basic reading processes as reflected in naming time. This approach is a variant of the task-switching procedure developed by Rogers and Monsell (1995) and subsequently adapted by Shafiullah and Monsell (1999) to study switch costs in naming time when the type of script is changed.

\section{Task Switching}

Rogers and Monsell (1995) found that subjects took longer to respond on trials where they were switching between two tasks alternating in a predictable AABB sequence despite the stimuli affording both tasks (e.g., T4). That is, subjects took longer to make an odd-even judgment if the previous trial required a consonant-vowel discrimination than if the previous trial required an oddeven judgment. Rogers and Monsell interpreted these data as evidence that switching from one task to another requires reconfiguring the task set, and that such reconfiguring takes time (see Pashler's 2000 review for a discussion of reconfiguration costs). 


\section{Script Switching}

Shafiullah and Monsell (1999) adapted the Rogers and Monsell (1995) procedure to examine switch costs between orthographies while holding the task constant. They found a small (15-msec) but significant cost when subjects had to switch between naming items written in kana (the Japanese syllabic script) and kanji (the Japanese ideographic script). Shafiullah and Monsell therefore argued that this switch cost is evidence that the different scripts require different processing mechanisms. ${ }^{2}$

\section{The Present Experiment}

The present experiment adapts Rogers and Monsell's (1995) alternating runs procedure to assess whether subjects can modify their reliance on lexical and sublexical knowledge when reading aloud low-frequency exception words and nonwords in alphabetic English. This is a simple extension of Shafiullah and Monsell (1999) in that here, both the task and the script remain constant. Thus, if switch costs are observed in the present experiment, they likely index changes in the use of lexical and sublexical knowledge when reading aloud.

The alternating runs procedure provides a novel method for encouraging subjects to reconfigure the processing system because there is no uncertainty with respect to the targets' lexicality on critical trials. This contrasts with previous studies that have compared naming under blocked or mixed-list naming, or under different priming conditions. The use of the alternating runs paradigm is also novel in that conditions can be established where the contextual control account predicts that response times will slow down on switch trials, whereas the response time homogenization account predicts that response times will speed up.

Any model of reading aloud that proposes a static solution to naming low-frequency exception words and nonwords (e.g., as in the present implementation of the DRC model, given that it uses a fixed parameter set) makes the straightforward prediction that there should be no switch cost. However, if the reading system is dynamic, and skilled readers differentially weight lexical and sublexical routines when naming exception words and nonwords, respectively, a cost should be observed for "switching" between reading these two types of stimuli (importantly, both from words to nonwords and vice versa).

\section{A Competitor: The Time Criterion Account}

According to the time criterion account, subjects attempt to homogenize the point in time when they release an articulation (Chateau \& Lupker, 2003; Kinoshita \& Lupker, 2002, 2003; Lupker, Brown, \& Columbo, 1997; Taylor \& Lupker, 2001). Mixing words that are named quickly in pure blocks with nonwords that are named slowly in pure blocks makes the fast words slow down and the slow nonwords speed up. ${ }^{3}$

The time criterion account is important because it has been argued to provide a better account of many results previously interpreted as supporting contextual control over lexical and sublexical processing in reading. Nevertheless, it is important to note that Lupker and colleagues have not claimed that context never modulates the relative reliance on lexical and nonlexical reading routes. Rather, they have argued that changes in response criterion provide a sufficient account of data that other investigators have interpreted as support for differential reliance on lexical and nonlexical routines.

If no contextual control is operating in the present experiment, and if subjects adjust their release point for articulation on a trial-by-trial basis, the response criterion account predicts that when a fast exception word is named after a slow nonword, its naming time will be slowed due to response time homogenization. This account also predicts that when a slow nonword is named after a fast exception word, its naming time will speed up due to response time homogenization. In contrast, the contextual control account predicts that because of process reconfiguration, longer RTs will occur for both the first exception word named after nonwords and the first nonword named after exception words. Thus, the two accounts make opposite predictions for naming slow nonwords after fast exception words.

\section{METHOD}

\section{Subjects}

Sixteen undergraduate students from the University of Waterloo were each paid $\$ 4.00$ to participate in the experiment. All subjects had normal or corrected-to-normal vision and were native English speakers.

\section{Materials}

Stimulus presentation was controlled by a Pentium IV $1.8 \mathrm{gHz}$ computer running Micro Experimental Laboratory 2 (MEL 2) software (Schneider, 1988). Vocal responses were collected using a Platronics LS1 microphone headset and a voice key assembly. Stimuli were displayed on a 17-in. ADI Microscan monitor.

\section{Stimuli}

The stimuli consisted of 100 irregular words taken from Roberts, Rastle, Coltheart, and Besner (2003) and Kinoshita and Lupker (2003) and 100 nonwords created from the irregular words by mixing onsets and rhymes. These stimuli can be seen in the Appendix.

\section{Procedure}

The lexical status of the initial trial (word/nonword) and whether an item would occur in a switch-or-stay trial were counterbalanced across subjects. The subjects were randomly assigned to one of four counterbalance conditions based on the order in which they were tested. The subjects were tested individually and were seated approximately $50 \mathrm{~cm}$ from the computer monitor.

The experiment was split into two blocks. The practice block consisted of 12 trials, whereas the experimental block consisted of 200 trials. Each trial began with a cross (+) displayed at the center of the screen. The subjects were instructed to fixate the cross and press the spacebar to initiate the trial. They were told that the fixation cross would disappear and be replaced by either a word or a nonword and that the type of stimulus that would appear followed a predictable sequence (i.e., word, word, nonword, nonword; or nonword, nonword, word, word). The subjects were instructed to name the item as quickly and accurately as possible. 


\section{RESULTS}

RTs for correct responses and percentage error can be seen in Figure 1. Trials on which there was an incorrect pronunciation $(8.3 \%)$ or voice key failure $(8.3 \%)$ were removed prior to the RT analysis. A pronunciation error was defined as an utterance that represented a clear mispronunciation of the word or nonword (i.e., an extra or deleted phoneme, regularization, or lexicalization).

\section{Reaction Times}

RTs for correct responses were first subjected to outlier removal with the criterion cutoff set at $\pm 3 S D$ s for each condition. This resulted in the removal of $1.2 \%$ of the correct RT data. The subject data were then analyzed using a repeated measures analysis of variance (ANOVA) with lexicality (words/nonwords) and switch (switch/stay) as factors. The subject data can be seen in Figure 1. The item data were analyzed by first converting individual subjects RTs for all items to $z$ scores so as to minimize the impact of subject variability on item latencies. The $z$-scored data were analyzed using a mixed-model ANOVA with lexicality as a between-items factor and switch as a repeated factor. Nonwords took longer to name than did words $\left[F_{1}(1,15)=41.0, M S_{\mathrm{e}}=1,789, p<.001\right.$; $\left.F_{2}(1,198)=70.0, M S_{\mathrm{e}}=0.113, p<.001\right]$, and naming time was longer on switch trials than on nonswitch trials $\left[F_{1}(1,15)=5.6, M S_{\mathrm{e}}=444, p<.05 ; F_{2}(1,198)=8.5\right.$, $\left.M S_{\mathrm{e}}=0.033, p<.01\right]$. There was no interaction between these two factors $(F \mathrm{~s}<1){ }^{4}$

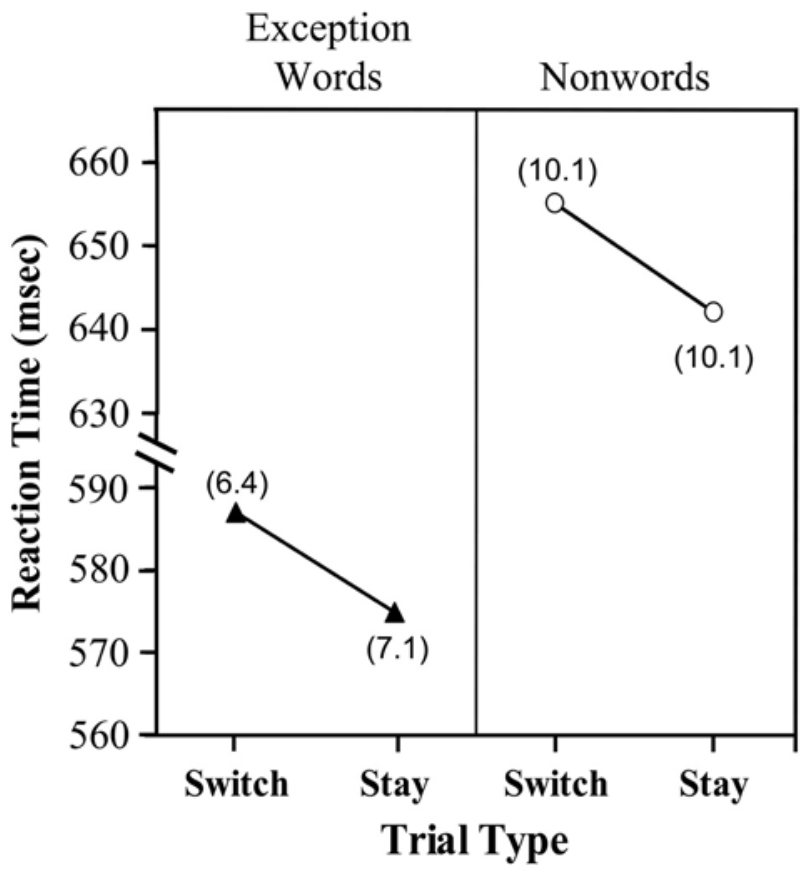

Figure 1: Mean reaction time (in milliseconds) and percentage error (in parentheses) for the subject analysis for words and nonwords as a function of switch and stay trials.

\section{Errors}

The subject data were analyzed using a repeated measures ANOVA with lexicality and switch as factors. The subject data can be seen in Figure 1. The item data were analyzed using a mixed-model ANOVA with lexicality as a between-items factor and switch as a repeated factor. More errors tended to be made for nonwords than for words $\left[F_{1}(1,15)=3.2, M S_{\mathrm{e}}=54.5, p<.10 ; F_{2}(1,198)=\right.$ $\left.3.3, M S_{\mathrm{e}}=264, p<.10\right]$. No other effects approached significance $(F \mathrm{~s}<1)$.

\section{DISCUSSION}

The purpose of the present experiment was to assess whether skilled readers modulate the use of lexical and sublexical spelling-sound correspondence knowledge when reading aloud. We assessed three accounts (static processing, response homogenization, and dynamic processing) by having subjects name exception words and nonwords in a predictable sequence. Static accounts of processing (such as the present implementation of the DRC model) predict that no switch cost will be seen, because there is no change in the reading system (the parameter settings on the two routes remain constant). Response homogenization predicts that trial-by-trial homogenization will slow the naming for a fast exception word after slow nonwords and, critically, speed up the naming of a slow nonword after fast exception words. A dynamic processing account predicts that the modulation of lexical and sublexical knowledge in the present context would result in a cost for switching from naming an exception word to naming a nonword, and vice versa. The observation of equivalent switch costs for words and nonwords in the present experiment is inconsistent with both the static processing and time criterion accounts. These results are, however, consistent with a dynamic processing account.

\section{Can the Present Results Be Explained by Lexical Checking?}

Lexical checking is defined by Kinoshita and Lupker (2003) as "consulting the phonological output lexicon in order to determine whether the code generated by the phonological coding process matches a code in the output lexicon" (p. 412). This idea was introduced by Lupker and colleagues (Kinoshita \& Lupker, 2003; Lupker et al., 1997) to account for data that is inconsistent with the time criterion account.

It is unclear how lexical checking by itself can account for the switch costs seen here. According to Kinoshita and Lupker (2003), the presence of exception words encourages subjects to perform lexical checking, which produces a small time cost for exception words while improving accuracy but a large time cost for nonwords. If lexical checking occurs on every trial, this will produce a main effect of lexicality but no switch costs. Alternatively, it might be argued that subjects engage in lexical checking only on switch trials. This predicts a larger effect on nonword switch trials than on word switch trials, given Kinoshita and Lupker's (2003) claim that lexical 
checking has a small impact on RT for naming an exception word and a large impact for naming a nonword. No such interaction was evident here.

It might be argued that the additive effects of lexicality and switching seen in the present experiment could be accounted for by somehow combining lexical checking and response time homogenization. However, in order to explain the switch cost seen for nonwords, a lexical checking/ response criterion account has to argue that lexical checking occurs on nonword switch trials. Although this is possible, it is unlikely for two reasons.

First, the lexical status of the items in the present experiment is $100 \%$ predictable. Kinoshita and Lupker (2003) argued that because lexically checking nonwords is "useless" and "counterproductive" (p. 412), it occurs more frequently as the ratio of words to nonwords increases. This can be rephrased in terms of uncertainty; the more likely it is that an item is a word, the more likely it is that the item will be lexically checked. In the present experiment, the probability that an item would be a word after the consecutive naming of two words was zero. It therefore seems unlikely that this strategy would have been employed here.

Second, lexical checking on nonword switch trials is inconsistent with the logic underlying response time homogenization. Previously, lexical checking has been invoked when an effect was found on RT, but no effect was predicted by response time homogenization. In the present study, response time homogenization predicted that subjects should make faster responses when switching from a fast exception word to a slow nonword, and lexical checking predicted that subjects should make slower responses. Thus, a combined account would have to explain why lexical checking occurs on nonword switch trials when doing so is intrinsically inconsistent with the time criterion account.

\section{Can the Present Results Be Explained by "Noticing?"}

A reviewer suggested that a minimal interpretation of the present switch costs is that subjects "notice" a change on switch trials (i.e., they might notice a change in the lexical status of the target). Our reply to this suggestion is that such "noticing" is essentially lexical checking, the problems of which have already been discussed at some length. Furthermore, it is interesting to note that Shafiullah and Monsell (1999) found no switch costs when subjects alternated between naming words from different linguistic categories in different orthographies (katakana and hiragana) that can be translated into sound via a single procedure. They argued that "it is not merely switching between two symbol sets that generates [switch] costs, but switching between scripts whose processing depends on different mechanisms or combinations of routes" (p. 595).

\section{Summary and Conclusions}

Previous studies have examined contextual control by manipulating list context (blocked vs. mixed, as in Baluch
\& Besner, 1991) or by priming different spelling-sound translation procedures (Zevin \& Balota, 2000). Lupker and colleagues have argued that a response time homogenization account provides a better explanation of these RT data. The present work adapted Shafiullah and Monsell's (1999) alternating runs methodology to assess whether reading can be contextually controlled. This procedure differs from other methods that provide evidence for contextual control in that it (1) encourages control by removing uncertainty about the targets' lexicality, and (2) assesses contextual control by examining switch costs rather than changes in the size of factor effects such as word frequency or spelling-sound regularity.

The critical result in the present experiment is the finding of an RT cost for switching between naming words and nonwords, and vice versa. This finding is inconsistent with static processing, response time homogenization, lexical checking, and a lexical checking/response time homogenization account. In contrast, the present results are naturally accounted for by a dynamic processing account where part of the reading system is reconfigured to handle different classes of stimuli more efficiently. Such switch costs could arise by adjusting the relative weights on the lexical and nonlexical routines (e.g., Baluch \& Besner, 1991; Rastle \& Coltheart, 1999) or by modulating the type of lexical knowledge that is brought to bear (e.g., Reynolds \& Besner, in press).

\section{Future Directions}

Several useful directions for future research are immediately evident. First, what impact does practice have on switch costs? Would practice with this procedure allow skilled readers to reconfigure processing before the stimulus appears, leading to elimination of the switch cost observed here, or is there a stimulus-driven component? (The latter might be assessed by displaying a masked prime before each trial and varying the probability of it being a word or a nonword.)

Second, what are the necessary conditions for switch costs to arise? For example, will high-frequency exception words and nonwords in English produce the pattern seen in the present experiment? This question is of theoretical interest because models like the DRC maintain that all exception words and nonwords are named via separate routines. A switch cost is therefore expected. In contrast, it is possible for parallel distributed processing models, such as Plaut, McClelland, Seidenberg, and Patterson (1996), to name high-frequency exception words and nonwords via a single routine (the orthography-tophonology routine). The absence of a switch cost with such stimuli would be consistent with such a model but not with the DRC.

Finally, are less skilled readers capable of the kind of control observed here? Failures of contextual control might provide a sensitive way of assessing problem readers. The paradigm provided here offers the means of answering such questions. 


\section{REFERENCES}

BALUCH, B., \& Besner, D. (1991). Visual word recognition: Evidence for strategic control of lexical and nonlexical routines in oral reading. Journal of Experimental Psychology: Learning, Memory, \& Cognition, 17, 644-652.

ChateaU, D., \& LUPKer, S. J. (2003). Strategic effects in word naming: Examining the route-emphasis versus time-criterion accounts. Journal of Experimental Psychology: Human Perception \& Performance, 29, 139-151.

Coltheart, M., Rastle, K., Perry, C., Langdon, R., \& Ziegler, J. (2001). DRC: A dual route cascaded model of visual word recognition and reading aloud. Psychological Review, 108, 204-256.

Frost, R. (1998). Toward a strong phonological theory of visual word recognition: True issues and false trails. Psychological Bulletin, 123, 71-99.

KANG, H., \& Simpson, G. B. (2001). Local strategic control of information in visual word recognition. Memory \& Cognition, 29, 648-655.

Kinoshita, S., \& LuPKer, S. J. (2002). Effects of filler type in naming: Change in time criterion or attentional control of pathways? Memory \& Cognition, 30, 1277-1287.

KINOSHITA, S., \& LUPKER, S. J. (2003). Priming and attentional control of lexical and sublexical pathways in naming: A reevaluation. Journal of Experimental Psychology: Learning, Memory, \& Cognition, 29, 405-415.

LUPKER, S. J., Brown, P., \& Colombo, L. (1997). Strategic control in a naming task: Changing routes or changing deadlines? Journal of Experimental Psychology: Learning, Memory, \& Cognition, 23, 570-590.

PASHLER, H. (2000). Task switching and multitask performance. In S. Monsell \& J. Driver (Eds.), Control of cognitive processes: Attention and performance XVIII (pp. 277-307). Cambridge, MA: MIT Press.

Plaut, D. C., McClelland, J. L., Seidenberg, M. S., \& Patterson, K. E. (1996). Understanding normal and impaired word reading: Computational principles in quasi-regular domains. Psychological Review, 103, 56-115.

Poulton, E. C. (1975). Range effects in experiments on people. American Journal of Psychology, 88, 3-32.

Raman, I., Baluch, B., \& Besner, D. (2004). On the control of visual word recognition: Changing routes versus changing deadlines. Memory \& Cognition, 32, 489-500.

Rastle, K., \& ColThEaRT, M. (1999). Serial and strategic effects in reading aloud. Journal of Experimental Psychology: Human Perception \& Performance, 25, 482-503.

REYNOLDS, M., \& BESNER, D. (in press). Basic processes in reading: A critical review of pseudohomophone effects in naming and a new implemented computational account. Psychonomic Bulletin \& Review.

Roberts, M. A., Rastle, K., Coltheart, M., \& Besner, D. (2003). When parallel processing in visual word recognition is not enough: New evidence from naming. Psychonomic Bulletin \& Review, 10, 405-414.

Rogers, R. D., \& Monsell, S. (1995). Costs of a predictable switch between simple cognitive tasks. Journal of Experimental Psychology: General, 124, 207-231.

SCHNEIDER, W. (1988). Micro Experimental Laboratory: An integrated system for IBM PC-compatibles. Behavior Research Methods, Instruments, \& Computers, 20, 206-217.
Shafiullah, M., \& Monsell, S. (1999). The cost of switching between kanji and kana while reading Japanese. Language \& Cognitive Processes, 14, 567-607.

TABOSSI, P., \& LAGHI, L. (1992). Semantic priming in the pronunciation of words in two writing systems: Italian and English. Memory \& Cognition, 20, 303-313.

TAYLOR, T. E., \& LUPKER, S. J. (2001). Sequential effects in naming: A time-criterion account. Journal of Experimental Psychology: Learning, Memory, \& Cognition, 27, 117-138.

Zevin, J. D., \& BAlota, D. A. (2000). Priming and attentional control of lexical and sublexical pathways during naming. Journal of Experimental Psychology: Learning, Memory, \& Cognition, 26, 121-135.

\section{NOTES}

1. Zevin and Balota (2000) argued that the most compelling evidence for contextual control in their experiments was a decrease in regularization errors for exception word targets when preceded by exception word primes as compared with nonword primes. Consistent with Zevin and Balota's results, Kinoshita and Lupker (2003) also reported a decrease in regularization errors when exception word targets were preceded by exception word primes rather than by nonword primes. However, the pattern reported by Kinoshita and Lupker (2003) is difficult to interpret because the proportion of errors that are regularizations increased under exception word primes.

2. Kang and Simpson (2001) reported experiments on naming words in Hangul and Hanza (the alphabetic and logographic Korean scripts, respectively) in which the nature of the upcoming script was cued on every trial. They argued that subjects could "set" themselves to process Hangul using the nonlexical routine despite other stimuli in the experiment appearing in Hanza. Two aspects of Kang and Simpson's Experiment 2 merit brief comment. First, because cuing was manipulated between subjects, it is difficult to tell whether high-frequency Hangul words slowed down or low-frequency Hangul words sped up in the cued condition. Given that high-frequency words have similar RTs under cued and uncued conditions, it appears that they were not affected by cuing. It therefore appears that low-frequency words sped up in the cued condition. In order to produce this pattern, the nonlexical route would have to be as fast as the lexical route for high-frequency words. We are aware of no data that support such an account (though, of course, this does not mean it is not true). A second point is that it is unclear (to us) why mixing Hangul and Hanza words promotes the use of a nonlexical route to read Hangul words when subjects were cued as to which kind of word was coming up, rather than using a lexical route to read Hangul.

3. Response time homogenization can be viewed as an example of a range effect that Poulton (1975) argued is a consequence of using a within-subjects design.

4. One reviewer noted that some of the nonwords could be read as pseudohomophones if an irregular pronunciation was used and suggested that this could somehow affect the results. The data were therefore reanalyzed with these items (and sown, since this item is a word rather than a nonword) excluded. This resulted in a 3-msec reduction in the main effect of lexicality, a $0.5-\mathrm{msec}$ reduction in the main effect of switch, and a $0.5-\mathrm{msec}$ reduction in the interaction. None of these changes were statistically significant. 
APPENDIX

\begin{tabular}{|c|c|c|c|c|c|c|c|}
\hline \multicolumn{4}{|c|}{ Low-Frequency Exception Words } & \multicolumn{4}{|c|}{ Nonwords } \\
\hline wad & broom & aunt & chasm & flad & troom & draunt & pasm \\
\hline beau & choir & bind & chord & weau & gloir & scind & yord \\
\hline bowl & chute & chef & cough & powl & wute & lef & wough \\
\hline chic & crepe & comb & dealt & gric & depe & gomb & fealt \\
\hline coup & dough & crow & dwarf & roup & drough & tsow & $\operatorname{arf}$ \\
\hline deaf & fiend & debt & flood & gheaf & tiend & brebt & pood \\
\hline dove & flown & dual & geese & chove & sown & wual & steese \\
\hline feud & ghoul & gist & glove & pleud & knoul & dist & swove \\
\hline glow & grind & heir & guild & fow & glind & bleir & dwuild \\
\hline hood & guise & hoof & knoll & crood & wuise & coof & choll \\
\hline isle & mould & knot & naive & nisle & stould & chot & baive \\
\hline lamb & niche & lieu & pearl & $\mathrm{amb}$ & siche & rieu & bearl \\
\hline limb & plaid & malt & realm & gimb & haid & swalt & healm \\
\hline monk & reign & have & rogue & bronk & heign & pook & shogue \\
\hline pear & scent & pier & shove & crear & stent & swier & sove \\
\hline pint & stead & sewn & steak & bint & ead & thewn & deak \\
\hline shoe & suede & soot & suite & coe & bruede & doot & muite \\
\hline sown & swarm & stow & sword & wown & marm & spow & nord \\
\hline swan & thumb & swap & tread & han & wumb & shap & gead \\
\hline tomb & weird & tsar & yacht & domb & sweird & knar & dacht \\
\hline warp & brooch & wart & douche & marp & swooch & sart & rouche \\
\hline wasp & dreamt & wolf & hearse & chasp & treamt & holf & gearse \\
\hline womb & hearth & worm & learnt & flomb & wearth & yorm & dearnt \\
\hline yolk & sponge & aisle & trough & cholk & stonge & daisle & lough \\
\hline blown & drought & brook & stealth & lown & wought & chook & cealth \\
\hline
\end{tabular}

(Manuscript received November 20, 2003; revision accepted for publication March 3, 2004.) 